Epidemiology and Psychiatric

Sciences

cambridge.org/eps

\section{Original Article}

Cite this article: Turner S, Harvey C, Hayes L, Castle D, Galletly C, Sweeney S, Shah S, Keogh L, Spittal MJ (2020). Childhood adversity and clinical and psychosocial outcomes in psychosis. Epidemiology and Psychiatric Sciences 29, e78, 1-10. https://doi.org/10.1017/ S2045796019000684

Received: 5 March 2019

Revised: 9 October 2019

Accepted: 19 October 2019

\section{Key words:}

Adverse life events; child abuse; childhood sexual abuse; childhood trauma; psychosis

Author for correspondence:

Matthew J. Spittal,

E-mail: m.spittal@unimelb.edu.au

\title{
Childhood adversity and clinical and psychosocial outcomes in psychosis
}

S. Turner ${ }^{1}$, C. Harvey ${ }^{2,3}$, L. Hayes ${ }^{4}$, D. Castle ${ }^{2,5}$, C. Galletly, ${ }^{6,7,8}$, S. Sweeney ${ }^{6,7}$, S. Shah ${ }^{9}$, L. Keogh ${ }^{10}$ and M. J. Spittal ${ }^{10}$ (D)

${ }^{1}$ Quality and Service Improvement, NorthWestern Mental Health, 300 Grattan St, Parkville, Victoria 3050, Australia; ${ }^{2}$ Department of Psychiatry, The University of Melbourne, Parkville, Victoria 3010, Australia; ${ }^{3}$ Psychosocial Research Centre, NorthWestern Mental Health, 130 Bell St, Coburg, Victoria 3058, Australia; ${ }^{4}$ Parenting Research Centre, 232 Victoria Parade, East Melbourne, Victoria 3002, Australia; ${ }^{5}$ St Vincent's Hospital, 41 Victoria Parade, Fitzroy, Victoria 3065, Australia; ${ }^{6}$ Discipline of Psychiatry, University of Adelaide, Adelaide, South Australia 5005, Australia; ${ }^{7}$ Ramsay Health Care (SA) Mental Health Services, 33 Park Tce, Gilbertson, South Australia 5081, Australia; ${ }^{8}$ North Adelaide Local Health Network, Ward 1G, Lyell McEwin Hospital, Haydown Road, Elizabeth Vale, South Australia 5112, Australia; ${ }^{9}$ Neuropsychiatric Epidemiology Research Unit, School of Psychiatry and Clinical Neurosciences, The University of Western Australia, 35 Stirling Highway, Crawley, Western Australia 6009, Australia and

${ }^{10}$ Melbourne School of Population and Global Health, The University of Melbourne, Parkville, Victoria 3010, Australia

\begin{abstract}
Aims. Associations between childhood abuse and various psychotic illnesses in adulthood are commonly reported. We aim to examine associations between several reported childhood adverse events (sexual abuse, physical abuse, emotional abuse, neglect and interpersonal loss) among adults with diagnosed psychotic disorders and clinical and psychosocial outcomes.

Methods. Within a large epidemiological study, the 2010 Australian National Survey of Psychosis (Survey of High Impact Psychosis, SHIP), we used logistic regression to model childhood adverse events (any and specific types) on 18 clinical and psychosocial outcomes. Results. Eighty percent of SHIP participants (1466/1825) reported experiencing adverse events in childhood (sexual abuse, other types of abuse and interpersonal loss). Participants reporting any form of childhood adversity had higher odds for 12/18 outcomes we examined. Significant associations were observed with all psychosocial outcomes (social dysfunction, victimisation, offending and homelessness within the previous 12 months, and definite psychosocial stressor within 12 months of illness onset), with the strongest association for homelessness (odds ratio $(\mathrm{OR})=2.82$ ). Common across all adverse event types was an association with lifetime depression, anxiety and a definite psychosocial stressor within 12 months of illness onset. When adverse event types were non-hierarchically coded, sexual abuse was associated with 11/18 outcomes, other types of abuse 13/18 and, interpersonal loss occurring in the absence of other forms of abuse was associated with fewer of the clinical and psychosocial outcomes, 4/18. When adverse events types were coded hierarchically (to isolate the effect of interpersonal loss in the absence of abuse), interpersonal loss was associated with lower odds of self-reproach $(\mathrm{OR}=0.70)$, negative syndrome $(\mathrm{OR}=0.75)$ and victimisation $(\mathrm{OR}=0.82)$. Conclusions. Adverse childhood experiences among people with psychosis are common, as are subsequent psychosocial stressors. Mental health professionals should routinely enquire about all types of adversities in this group and provide effective service responses. Childhood abuse, including sexual abuse, may contribute to subsequent adversity, poor psychosocial functioning and complex needs among people with psychosis. Longitudinal research to better understand these relationships is needed, as are studies which evaluate the effectiveness of preventative interventions in high-risk groups.
\end{abstract}

\section{Introduction}

According to global estimates, 7-36\% of women and 3-29\% of men report being victims of sexual abuse during childhood (Pereda et al., 2009). In Australia, the prevalence is 14-20\% for women and 3-10\% for men (Moore et al., 2010). The evidence increasingly supports strong associations between childhood sexual abuse and psychotic disorders in later life. Retrospective studies show that a high proportion of people with psychotic disorders have previously experienced sexual abuse (Bendall et al., 2008; Cutajar et al., 2010; Bebbington et al., 2011; Mauritz et al., 2013). Research has also shown strong associations between schizophrenia, as well as other mental disorders including depression, anxiety, post-traumatic stress disorder, dissociative disorders, substance dependence and self-harm and childhood abuse, including sexual, physical and emotional abuse, and neglect (Van der Kolk et al., 2005; Cutajar et al., 2010; Gonzalez et al., 2012; Varese et al., 2012; Matheson et al., 2013; van Nierop et al., 2015; 
Palmier-Claus et al., 2016). Although it has long been recognised that stressful life events and difficulties contribute to depression and anxiety (see Craig, 2010), less is known about how relatively common adverse experiences (e.g. parental separation) may contribute to psychoses.

Psychosocial outcomes refer to a person's recovery in areas such as vocational and social functioning (Killackey et al., 2015; Stolerman and Price, 2015). This is an important but neglected area of research (Fossey and Harvey, 2001; Misiak et al., 2017). Poor psychosocial outcomes directly affect mental health consumers and their families as well as contributing to a general impact on quality of life (National Mental Health Commission, 2014; Cotter et al., 2015; Poon et al., 2017). For these reasons, understanding the antecedents of poor psychosocial outcomes is relevant for consumers and families, clinicians, policymakers and researchers alike (Felitti et al., 1998). Improved understanding of psychosocial stressors both preceding and at illness onset also offers an opportunity for prevention and early intervention. In a previous study, we examined the relationship between childhood abuse and psychosis and reported high rates (31\%) of any childhood abuse before illness onset (Shah et al., 2014), but our investigation mostly focused on clinical and physical health outcomes, rather than psychosocial outcomes and the recurrence of psychosocial stressors.

Research on psychosocial outcomes among people with psychosis has highlighted that individuals with significant abuse histories often have difficulty with employment, housing and social functioning (Gil et al., 2009; Alameda et al., 2015; Cotter et al., 2015). Other studies have drawn a connection between early and subsequent exposure to psychosocial stressors (e.g. victimisation, homelessness, crime and offending) and an increased likelihood of developing a psychotic response (Rosenberg et al., 2007; Pluck et al., 2011; Lataster et al., 2012). These findings are interesting but limited because of a reliance on single questions to assess trauma - usually defined as child abuse (physical and sexual) or sexual abuse only; little consideration of potential confounders (for instance, family history of mental illness and cannabis use); examination of a small number of outcomes and limited power with only a small number of individuals experiencing the exposure or the outcome (Gil et al., 2009; Hooven et al., 2012; Berthelot et al., 2015; Trauelsen et al., 2015; Cristobal-Narvaez et al., 2016; Gallagher and Jones, 2016; Holshausen et al., 2016).

Our aim was to address some of the gaps and limitations in previous studies by examining all forms of abuse and other negative experiences in childhood and their relationships with a range of outcome variables, adjusting for a wide variety of potential confounders. These are: age (Bentall et al., 2012), sex (Bentall et al., 2012; Matheson et al., 2013), currently married or previously married (Bendall et al., 2008), presence of children or step children (Bendall et al., 2008), born in Australia (Varese et al., 2012), highest qualification is a school-level qualification (Bendall et al., 2008; Bentall et al., 2012; Varese et al., 2012), family history of mental illness (Bendall et al., 2008; Varese et al., 2012; Matheson et al., 2013), socioeconomic status of the participant's residence (Bentall et al., 2012; Varese et al., 2012) and lifetime cannabis use (Janssen et al., 2004; Bendall et al., 2008; Varese et al., 2012). Specifically, we examined the association between exposure to diverse adverse childhood events and a number of mental health symptoms and diagnoses (Bendall et al., 2008; Varese et al., 2012; Van Nierop et al., 2015) as well as important psychosocial outcomes (Rosenberg et al., 2007; Gilbert et al.,
2009; Alameda et al., 2015). Our primary hypothesis was that any adverse event in childhood (defined as sexual, physical and emotional abuse and neglect, and interpersonal loss) would be associated with clinical and psychosocial impairment. Our secondary hypothesis was that different types of abuse as well as interpersonal loss would also be associated with impairment.

\section{Method}

\section{Overview}

This study analysed data collected from the 2010 Australian National Survey of Psychosis (Survey of High Impact Psychosis, SHIP) (Morgan et al., 2012, 2014). The survey methodology is described in detail elsewhere (Morgan et al., 2012; Shah et al., 2014). A cross-sectional survey was conducted across seven catchment sites in five states. Because psychosis is comparatively rare, sampling was done in two stages. A census of people with psychosis was taken from three mutually exclusive groups: people in contact with public mental health services during the census month (March 2010); people not in contact with those services, but in contact with non-government organisations supporting people with mental illness during the census month and people not in contact with either of these two services during the census month but in contact with public mental health services during the preceding 11 months. All those identified in the census were screened using the Psychosis Screen (Jablensky et al., 2000) and 7955 screened positive. From this, a random sample ( $n=1825)$ stratified by age (18-34 years and $35-65$ years) were selected and interviewed by trained mental health professionals. The response rate was $44 \%$ and there was no evidence of selection bias (Morgan et al., 2012). The study was approved by ethics committees at the seven study sites. Participants provided written, informed consent.

\section{Adverse event variables}

The primary exposure of interest was the reported occurrence of an adverse event in childhood, defined as experiencing sexual abuse, other abuse (physical abuse, emotional abuse and neglect) or interpersonal loss (loss of a parent, sibling or close relative, parental separation or divorce). Only cases where the adverse event occurred during childhood ( $\leqslant 18$ years) and before the onset of psychotic illness were included.

Our adverse event variables were constructed from responses to a series of questions. Participants were initially asked the following questions: 'Did your parents separate or divorce when you were a child?'; 'Did you suffer the loss of a parent when you were a child?'; 'Did you suffer the loss of a brother or sister when you were a child?'; 'Did you suffer the loss of another close relative when you were a child?' and 'Were there any other distressing or traumatic events in your childhood?'. The age when each event happened was also recorded. These first four questions were used to construct a variable representing the presence or absence of interpersonal loss in childhood.

If participants reported any other distressing or traumatic events, then interviewers took notes of what had happened. These qualitative responses were coded into two main categories: sexual abuse and other types of abuse (defined as physical abuse, emotional abuse, neglect and other forms of abuse), based on Australian guidelines (Australian Institute of Health and Welfare, 2012). Further details about these variables are 
described elsewhere (Rosenman and Rodgers, 2004; Shah et al., 2014)

We constructed a variable representing the occurrence of any of these adverse events in childhood $(0 v . \geqslant 1)$. We also separated them out into three variables: sexual abuse (yes, no), physical and emotional abuse and neglect (yes, no) and interpersonal loss (yes, no). This coding allowed for the possibility that an individual could experience more than one type of adverse event. Finally, to understand the effect of each type of adverse event in isolation (in particular, childhood adversity in the absence of abuse), we constructed three hierarchically coded variables. Reported sexual abuse trumped physical and emotional abuse and neglect and, physical and emotional abuse and neglect trumped interpersonal loss, such that individuals could only be counted once in the set of analyses.

\section{Outcome variables}

The SHIP interview schedule included a number of embedded instruments (Morgan et al., 2012). Symptom profile and mental health diagnoses were determined using the Diagnostic Interview for Psychosis (DIP) (Castle et al., 2006). The DIP allows lifetime, previous year and previous 4 weeks' ratings of symptoms; diagnoses can be assigned according to ICD-10 (World Health Organisation, 1992) and DSM-IV (American Psychiatric Association, 2000) criteria. The DIP contains selected interview questions and probes from the WHO Schedules for Clinical Assessment in Neuropsychiatry (Wing et al., 1990) mapped on the OPCRIT (McGuffin et al., 1991). DIP scores are fed into the computerised OPCRIT algorithm which produces diagnoses according to, in this case, the 10th edition of the International Classification of Disease (ICD-10) (World Health Organisation, 2015).

Using the DIP, we identified six symptoms or symptom clusters occurring over the lifetime. These were depressive symptoms, mania (elevated or irritable mood), self-reproach, delusions, hallucinations and subjective thought disorder. We used ratings of suicidal thoughts in the previous 4 weeks and self-harm in the previous 12 months. We also identified the presence of two additional symptoms and syndromes: anxiety in the previous 12 months using relevant Schedules for Clinical Assessment in Neuropsychiatry items (SCAN) (Wing et al., 1999; Bolton, 2010), and a count of the number of negative symptoms over the previous 12 months (using SCAN items of the Carpenter deficits syndrome) (Kirkpatrick et al., 1989).

We identified three diagnoses occurring over the lifetime, all using ICD-10 criteria (World Health Organisation, 1992). These were alcohol and other substance abuse and dependence (excluding cannabis), and diagnoses for affective psychosis and nonaffective psychosis. Affective psychosis was defined as a diagnosis of bipolar disorder or mania (both in the presence of psychotic symptoms); non-affective psychosis by a diagnosis of schizophrenia, schizoaffective disorder or delusional disorders and other non-organic psychoses. Diagnoses of substance use and affective psychosis/non-affective psychosis were not mutually exclusive due to possible comorbidity.

Finally, we included five variables measuring psychosocial outcomes. Four of these were based on previous 12 months and were: behavioural and social functioning including role performance (assessed using the Personal and Social Performance Scale (PSP) (Morosini et al., 2000)); experience of victimisation (ABS Crime and Safety Survey) (Australian Bureau of Statistics,
2005); perpetration of crime or offending (extracted from the section on criminality within the Opiate Treatment Index (Darke et al., 1991)) and homelessness (Homelessness and Mental Health Survey (Robinson, 2003)). The fifth psychosocial outcome was the presence of a definite psychosocial stressor within 12 months of the first psychotic episode.

PSP scores range from 0 to 100 , where 100 represents excellent functioning. The recognised cut-point of 70 or less is used to indicate poor functioning (scores above this value indicate the absence of disability or only mild difficulties). Experience of victimisation was measured using four items (number of times the participant was a victim of a break-in, theft, assault or was threatened with assault) and coded $0 v . \geqslant 1$. Homelessness was measured by the number of homeless days in the previous year (coded $0 v . \geqslant 1$ day). Perpetration of crime was measured using a positive response to the question: in the last 12 months have you committed any crimes such as break and enter, shoplifting, dealing drugs, forging cheques, armed robbery or assault?' Psychosocial stressors included potentially significant and/or threatening events that occurred during the 12 months preceding onset of psychosis such as: important problems with primary support groups, educational problems, occupational problems, housing problems, economic problems, legal problems and other problems.

\section{Statistical analysis}

For our primary analysis we used logistic regression to model the effects of exposure to any adverse event on each of the 18 outcome variables. As a sensitivity analysis, we then repeated the analysis restricted to people with non-affective psychosis ('sensitivity analysis 1') and affective psychosis ('sensitivity analysis 2'). For our secondary analysis we modelled separately the effects of exposure to each of the specific types of abuse or loss (sexual abuse, physical and emotional abuse and neglect, interpersonal loss) on the outcome variables. Finally and as a third sensitivity analysis, we modelled the effect of the three specific types of abuse or loss using the hierarchically coded variables whereby sexual abuse trumped physical and emotional abuse and neglect which trumped interpersonal loss ('sensitivity analysis 3 '). To account for potential confounding between the adverse event variables and the outcome variables, all models included age (18-25, 26$35,36-45,46-65)$, sex, currently married or in a de facto relationship or previously married (yes, no), presence of children or step children (yes, no), born in Australia (yes, no), highest qualification is a school-level qualification (yes, no), family history of mental illness (yes, no), socioeconomic status of the participant's residence (in quintiles) and lifetime cannabis use (yes, no). Socioeconomic status was based on the Index of Relative Socioeconomic Disadvantage (IRSED) (Australian Bureau of Statistics, 2011). We report the effect sizes for the adverse event exposures only.

\section{Results}

\section{Characteristics of the sample}

Among the 1825 participants, $14 \%$ were aged $18-25$ years and $28 \%$ were aged $46-65$ years (Table 1). Most were male $(60 \%)$, born in Australia (82\%), and had a family history of mental illness (58\%). Forty-nine percent were married/in a de facto relationship or had been married and $40 \%$ had children or step children. Thirty-five percent lived in neighbourhoods of low socio- 
Table 1. Characteristics of participants, $n=1825$

\begin{tabular}{|c|c|c|}
\hline & Number & Percent \\
\hline \multicolumn{3}{|l|}{ Covariates } \\
\hline \multicolumn{3}{|l|}{ Age } \\
\hline $18-25$ & 247 & 14 \\
\hline $26-35$ & 568 & 31 \\
\hline $36-45$ & 497 & 27 \\
\hline $46-65$ & 513 & 28 \\
\hline Male & 1087 & 60 \\
\hline Currently married or has been married & 891 & 49 \\
\hline Has children or step children & 723 & 40 \\
\hline Born in Australia & 1500 & 82 \\
\hline No tertiary qualification & 919 & 51 \\
\hline Family history of mental illness & 1060 & 58 \\
\hline \multicolumn{3}{|l|}{ Socioeconomic status (IRSED, quintile) } \\
\hline 1 (Poorest) & 292 & 16 \\
\hline 2 & 340 & 19 \\
\hline 3 & 424 & 23 \\
\hline 4 & 445 & 24 \\
\hline 5 (Richest) & 320 & 18 \\
\hline Lifetime cannabis use & 1211 & 67 \\
\hline \multicolumn{3}{|l|}{ Exposure to childhood adverse event } \\
\hline Experienced any adverse event & 1466 & 80 \\
\hline Experienced sexual abuse & 301 & 16 \\
\hline Experienced other types of abuse & 305 & 17 \\
\hline Experienced interpersonal loss & 1317 & 72 \\
\hline \multicolumn{3}{|l|}{ Outcome variables } \\
\hline Depression (lifetime) & 1469 & 80 \\
\hline Mania (lifetime) & 794 & 44 \\
\hline Self-reproach (lifetime) & 582 & 32 \\
\hline Delusions (lifetime) & 1583 & 87 \\
\hline Hallucinations (lifetime) & 1440 & 79 \\
\hline Subjective thought disorder (lifetime) & 857 & 47 \\
\hline Suicidal thoughts (past 4 weeks) & 210 & 12 \\
\hline Self-harm (past 12 months) & 310 & 17 \\
\hline Anxiety (past 12 months) & 1145 & 63 \\
\hline Negative syndrome (past 12 months) & 1291 & 71 \\
\hline $\begin{array}{l}\text { Alcohol and other substance dependence, } \\
\text { excluding cannabis (lifetime, ICD-10) }\end{array}$ & 1071 & 59 \\
\hline Affective psychosis (lifetime, ICD-10) & 400 & 22 \\
\hline Non-affective psychosis (lifetime, ICD-10) & 1242 & 68 \\
\hline Social dysfunction (past 12 months) & 1502 & 82 \\
\hline Victimisation (past 12 months) & 717 & 39 \\
\hline Crime/offending (past 12 months) & 201 & 11 \\
\hline Homelessness (past 12 months) & 159 & 9 \\
\hline $\begin{array}{l}\text { Definite psychosocial stressor within } 12 \text { months } \\
\text { of first episode }\end{array}$ & 1147 & 63 \\
\hline
\end{tabular}

Note: Numbers may not sum to 1825 due to missing data. IRSED is Index of Relative Socioeconomic Disadvantage. economic status (lowest two IRSED quintiles). Forty-seven percent met the ICD-10 criteria for schizophrenia, $16 \%$ schizoaffective disorder, $18 \%$ bipolar disorder or mania (both with psychotic symptoms), $9 \%$ severe depression without psychosis, 5\% delusional disorder, $4 \%$ depressive psychosis, $1 \%$ screened positive for psychosis but did not meet full ICD-10 criteria for psychosis. About 9\% were classified as dependent drinkers using the AUDIT and over two-thirds had a lifetime history of cannabis use. The prevalence of the outcomes ranged from $9 \%$ for homelessness ( $\leqslant 12$ months) to $87 \%$ reporting delusions (lifetime). Concerning functional outcomes other than homelessness, 39\% reported victimisation, $11 \%$ had been involved in some type of crime and offending and $82 \%$ reported social dysfunction (all $\leqslant 12$ months).

\section{Exposure to adverse events}

Eighty percent of participants had experienced an adverse event in childhood - 16\% had experienced sexual abuse, $17 \%$ had experienced other forms of abuse and $72 \%$ had experienced interpersonal loss. Parental separation or divorce was the most common interpersonal loss (40\%).

\section{Outcomes associated with any adverse event}

The occurrence of any adverse childhood event was associated with increased odds of 12/18 symptoms, diagnoses and psychosocial outcomes (Table 2). For instance, those who had experienced a childhood adverse event had 1.68 times higher odds of having depression compared with those who had not experienced an adverse event. The largest effect sizes were for homelessness (odds ratio $(\mathrm{OR})=2.82$ ), participation in crime and offending in the previous 12 months $(\mathrm{OR}=1.95)$ and suicidal thoughts in the previous 4 weeks $(\mathrm{OR}=1.90)$. Of the three diagnoses examined, the only association observed was for alcohol and other substance dependence $(\mathrm{OR}=1.39)$.

In a sensitivity analysis where the sample was restricted to people with non-affective psychosis, these findings largely held, with any adverse event in childhood still associated with eight outcomes. Most ORs were of similar magnitude to the primary analysis. In a second sensitivity analysis restricted to people with affective psychosis, an adverse event in childhood was associated with only three outcomes. Any adverse event in childhood was associated with lower odds of mania $(\mathrm{OR}=0.28)$ and higher odds of self-reproach $(\mathrm{OR}=2.06)$ and a definite psychosocial stressor within 12 months of first episode $(\mathrm{OR}=1.87)$. Some large ORs were non-significant, suggesting that the reduced sample size used for these analyses may have been underpowered to detect effects.

\section{Outcomes associated with specific adverse events}

Table 3 shows the association between three specific adverse events and the outcomes under investigation. Sexual abuse in childhood predicted 10/18 outcomes. Other forms of abuse (physical abuse, emotional abuse and neglect) were associated with 13 outcomes, and experiencing interpersonal loss (loss of a parent, loss of a sibling, loss of a close relative, parental separation or divorce) was associated with four outcomes. Common across all types of adverse events was the association with depression, anxiety and a definite psychosocial stressor within 12 months of first episode. 
Table 2. Logistic regression models estimating the effect of any adverse event on 18 variables measuring symptoms, diagnoses and functioning (primary and sensitivity analyses)

\begin{tabular}{|c|c|c|c|c|c|c|}
\hline \multirow[b]{4}{*}{ Outcome } & $\begin{array}{l}\text { Primary } \\
\text { analysis }\end{array}$ & \multirow[b]{4}{*}{$p$-value } & $\begin{array}{l}\text { Sensitivity } \\
\text { analysis } 1\end{array}$ & \multicolumn{3}{|c|}{$\begin{array}{l}\text { Sensitivity } \\
\text { analysis } 2\end{array}$} \\
\hline & \multirow[t]{2}{*}{$n=1793$} & & \multicolumn{2}{|l|}{$\begin{array}{l}\text { Non-affective } \\
\text { psychosis }\end{array}$} & \multicolumn{2}{|l|}{$\begin{array}{l}\text { Affective } \\
\text { psychosis }\end{array}$} \\
\hline & & & $n=1222$ & & $n=391$ & \\
\hline & AOR $(95 \% \mathrm{CI})$ & & AOR $(95 \% \mathrm{Cl})$ & $p$-value & AOR $(95 \% \mathrm{CI})$ & $p$-value \\
\hline \multicolumn{7}{|l|}{ Symptom and syndrome profile } \\
\hline Depression (lifetime) & $1.68(1.26-2.24)$ & $<0.001$ & $1.61(1.17-2.20)$ & 0.003 & $1.40(0.50-3.95)$ & 0.522 \\
\hline Mania (lifetime) & $1.09(0.85-1.41)$ & 0.486 & $1.31(0.95-1.81)$ & 0.100 & $0.28(0.10-0.76)$ & 0.012 \\
\hline Self-reproach (lifetime) & $1.21(0.92-1.60)$ & 0.166 & $1.08(0.77-1.53)$ & 0.653 & $2.06(1.15-3.68)$ & 0.015 \\
\hline Delusions (lifetime) & $0.98(0.68-1.41)$ & 0.895 & $1.25(0.68-2.31)$ & 0.476 & $1.05(0.49-2.26)$ & 0.893 \\
\hline Hallucinations (lifetime) & $1.40(1.05-1.85)$ & 0.020 & $1.54(1.04-2.27)$ & 0.030 & $1.76(0.99-3.13)$ & 0.055 \\
\hline Subjective thought disorder (lifetime) & $1.49(1.16-1.91)$ & 0.002 & $1.64(1.22-2.21)$ & 0.001 & $1.31(0.71-2.41)$ & 0.391 \\
\hline Suicidal thoughts (past 4 weeks) & $1.90(1.20-3.01)$ & 0.006 & $2.01(1.09-3.71)$ & 0.025 & $1.43(0.65-3.15)$ & 0.379 \\
\hline Self-harm (past 12 months) & $1.63(1.11-2.40)$ & 0.013 & $1.35(0.82-2.20)$ & 0.235 & $2.26(0.98-5.22)$ & 0.055 \\
\hline Anxiety (past 12 months) & $1.54(1.20-1.97)$ & 0.001 & $1.48(1.10-1.98)$ & 0.009 & $1.34(0.73-2.45)$ & 0.347 \\
\hline Negative syndrome (past 12 months) & $0.98(0.75-1.29)$ & 0.903 & $0.80(0.56-1.12)$ & 0.191 & $1.41(0.78-2.54)$ & 0.255 \\
\hline \multicolumn{7}{|l|}{ Diagnosis } \\
\hline $\begin{array}{l}\text { Alcohol and other substance dependence } \\
\text { excluding cannabis (lifetime) }\end{array}$ & $1.39(1.05-1.83)$ & 0.020 & $1.26(0.90-1.76)$ & 0.184 & $1.62(0.87-3.02)$ & 0.126 \\
\hline Affective psychosis (lifetime) & $1.06(0.78-1.45)$ & 0.703 & - & - & - & - \\
\hline Non-affective psychosis (lifetime) & $0.88(0.66-1.16)$ & 0.351 & - & - & - & - \\
\hline \multicolumn{7}{|l|}{ Functioning } \\
\hline Social dysfunction (past 12 months) & $1.51(1.10-2.07)$ & 0.010 & $1.40(0.93-2.10)$ & 0.106 & $1.55(0.80-3.00)$ & 0.191 \\
\hline Victimisation (past 12 months) & $1.56(1.20-2.03)$ & 0.001 & $1.53(1.12-2.10)$ & 0.008 & $1.14(0.63-2.05)$ & 0.663 \\
\hline Crime/offending (past 12 months) & $1.95(1.18-3.21)$ & 0.009 & $1.60(0.89-2.87)$ & 0.117 & $2.90(0.98-8.55)$ & 0.054 \\
\hline Homelessness (past 12 months) & $2.82(1.52-5.22)$ & 0.001 & $2.35(1.18-4.67)$ & 0.015 & $3.28(0.71-15.15)$ & 0.128 \\
\hline $\begin{array}{l}\text { Definite psychosocial stressor within } 12 \\
\text { months of first episode }\end{array}$ & $1.74(1.34-2.24)$ & $<0.001$ & $2.00(1.47-2.72)$ & $<0.001$ & $1.87(1.01-3.43)$ & 0.045 \\
\hline
\end{tabular}

Significant values are in bold.

Note: Models adjusted for age, sex, marital status, parental status, born in Australia, highest qualification obtained, family history of mental illness, socioeconomic status and lifetime cannabis use.

The relationship between sexual abuse in childhood and the outcome variables was strongest for depression $(\mathrm{OR}=2.16)$, selfharm $(\mathrm{OR}=1.79)$ and a definite psychosocial stressor within 12 months of first episode $(\mathrm{OR}=1.66)$. The effect of other forms of abuse was strongest for homelessness $(\mathrm{OR}=1.92)$, participation in crime and offending $(\mathrm{OR}=1.84)$ and victimisation $(\mathrm{OR}=1.80)$. Interpersonal loss in childhood was associated with homelessness $(\mathrm{OR}=1.91)$, depression $(\mathrm{OR}=1.41)$, anxiety $(\mathrm{OR}=1.26)$ and definite psychosocial stressor within 12 months of first episode $(\mathrm{OR}=1.26)$

In the third sensitivity analysis where abuse and loss were coded hierarchically, the results for sexual abuse and other forms of abuse were broadly similar to that reported in the nonhierarchically coded analysis (Table 4). However, a different picture emerged for interpersonal loss. This form of adversity (in the absence of the other two) was associated with lower odds of self-reproach $(\mathrm{OR}=0.70)$, negative syndrome $(\mathrm{OR}=0.75)$ and victimisation $(\mathrm{OR}=0.82)$.

\section{Discussion}

This study is unique in using a large representative population of people with psychosis to examine the prevalence of diverse adverse events in childhood and their relationship with symptomatic and psychosocial outcomes. It adds to previous research by collecting systematic data on a wide range of clinical and psychosocial outcomes, some previously unexamined in this context (including homelessness and the presence of a definite psychosocial stressor within 12 months of illness onset).

Four in five Australians living with psychosis reported experiencing some form of adverse event in childhood and approximately one in six reported exposure to childhood sexual abuse on at least one occasion before 18 years of age. However, since ascertainment of abuse histories by retrospective rather than prospective methods (Hooven et al., 2012; Varese et al., 2012), or by face-to-face interviews compared with confidential self-report measures (Bendall et al., 2008), tends to underestimate this type of abuse, we expect this figure may be greater. Our reported prevalence of childhood 
Table 3. Secondary analysis: logistic regression models estimating the effect of sexual abuse, other abuse and interpersonal loss on 18 variables measuring symptoms, diagnoses and measures of functioning, $n=1793$

\begin{tabular}{|c|c|c|c|c|c|c|}
\hline Outcomes & $\begin{array}{l}\text { Sexual abuse } \\
\text { AOR }(95 \% \mathrm{Cl})\end{array}$ & $p$-value & $\begin{array}{l}\text { Other abuse } \\
\text { AOR }(95 \% \mathrm{Cl})\end{array}$ & $p$-value & 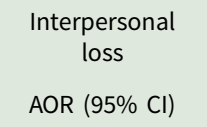 & $p$-value \\
\hline \multicolumn{7}{|l|}{ Symptom and symptom clusters } \\
\hline Depression (lifetime) & $2.16(1.38-3.37)$ & 0.001 & $1.53(1.05-2.22)$ & 0.027 & $1.41(1.08-1.83)$ & 0.012 \\
\hline Mania (lifetime) & $1.25(0.96-1.64)$ & 0.101 & $0.97(0.74-1.25)$ & 0.790 & $1.03(0.83-1.29)$ & 0.780 \\
\hline Self-reproach (lifetime) & $1.64(1.25-2.15)$ & $<0.001$ & $1.54(1.18-2.01)$ & 0.001 & $1.00(0.79-1.26)$ & 0.999 \\
\hline Delusions (lifetime) & $1.04(0.71-1.52)$ & 0.833 & $1.39(0.92-2.09)$ & 0.116 & $0.92(0.66-1.27)$ & 0.600 \\
\hline Hallucinations (lifetime) & $1.53(1.08-2.18)$ & 0.017 & $1.45(1.03-2.03)$ & 0.032 & $1.25(0.97-1.61)$ & 0.087 \\
\hline Subjective thought disorder (lifetime) & $1.64(1.25-2.15)$ & $<0.001$ & $1.33(1.03-1.73)$ & 0.029 & $1.14(0.91-1.42)$ & 0.248 \\
\hline Suicidal thoughts (last 4 weeks) & $1.56(1.08-2.26)$ & 0.018 & $1.72(1.21-2.44)$ & 0.003 & $1.25(0.88-1.78)$ & 0.209 \\
\hline Self-harm (past 12 months) & $1.79(1.31-2.45)$ & $<0.001$ & $1.55(1.13-2.12)$ & 0.006 & $1.27(0.93-1.72)$ & 0.131 \\
\hline Anxiety (past 12 months) & $1.56(1.16-2.11)$ & 0.003 & $1.64(1.23-2.18)$ & 0.001 & $1.26(1.01-1.58)$ & 0.037 \\
\hline Negative syndrome (past 12 months) & $1.39(1.03-1.88)$ & 0.031 & $1.40(1.04-1.87)$ & 0.027 & $1.01(0.80-1.28)$ & 0.926 \\
\hline \multicolumn{7}{|l|}{ Diagnosis } \\
\hline $\begin{array}{l}\text { Alcohol and other substance dependence } \\
\text { excluding cannabis (lifetime) }\end{array}$ & $1.17(0.86-1.59)$ & 0.307 & $1.21(0.90-1.63)$ & 0.212 & $1.16(0.91-1.48)$ & 0.225 \\
\hline Affective psychosis (lifetime) & $1.22(0.90-1.65)$ & 0.197 & $1.13(0.83-1.53)$ & 0.439 & $0.86(0.66-1.11)$ & 0.254 \\
\hline Non-affective psychosis (lifetime) & $0.96(0.72-1.27)$ & 0.777 & $0.98(0.74-1.29)$ & 0.883 & $0.98(0.78-1.25)$ & 0.892 \\
\hline \multicolumn{7}{|l|}{ Functioning } \\
\hline Social dysfunction (past 12 months) & $1.40(0.98-2.00)$ & 0.066 & $1.48(1.03-2.14)$ & 0.036 & $1.21(0.91-1.60)$ & 0.193 \\
\hline Victimisation (past 12 months) & $1.48(1.14-1.94)$ & 0.004 & $1.80(1.39-2.32)$ & $<0.001$ & $1.19(0.95-1.49)$ & 0.121 \\
\hline Crime/offending (past 12 months) & $1.44(0.95-2.18)$ & 0.084 & $1.84(1.28-2.66)$ & 0.001 & $1.31(0.89-1.92)$ & 0.173 \\
\hline Homelessness (past 12 months) & $1.00(0.62-1.62)$ & 0.994 & $1.92(1.29-2.87)$ & 0.001 & $1.91(1.20-3.02)$ & 0.006 \\
\hline $\begin{array}{l}\text { Definite psychosocial stressor within } 12 \\
\text { months of first episode }\end{array}$ & $1.66(1.21-2.26)$ & 0.001 & $1.71(1.27-2.30)$ & $<0.001$ & $1.26(1.00-1.58)$ & 0.049 \\
\hline
\end{tabular}

Significant values are in bold.

Note: Models adjusted for age, sex, marital status, parental status, born in Australia, highest qualification obtained, family history of mental illness, socioeconomic status and lifetime cannabis use.

sexual abuse within this population falls within previously reported ranges (e.g. Gustafson and Sarwer, 2004; Casey and Nurius, 2005; Messman-Moore et al., 2010). These findings support previously reported increased rates of childhood adversity in people with diagnoses of mental illness when compared to the general population (Morgan and Fisher, 2007; Cutajar et al., 2010; McCabe et al., 2012; Mauritz et al., 2013).

The other key finding is that more than one type of adversity appears to be associated with the development of psychosis (van Nierop et al., 2014). Our results also suggest that childhood interpersonal loss, occurring in the absence of other forms of abuse, contributes to less severe symptom and functioning impacts within the population of people with psychosis.

A number of functional outcomes were strongly associated with physical and emotional abuse and neglect, especially victimisation, offending and homelessness, adding to a growing body of evidence about the functional sequelae of childhood adversity (e.g. Cantor-Graae, 2007; Rosenberg et al., 2007; Gil et al., 2009). As in the Gil study, the strongest associations were with reported abuse other than sexual abuse. This highlights the potentially pervasive negative impact of all forms of childhood adversity in this sub-population and the likely contribution of adverse childhood experiences to psychosocial disability and complex needs among people with psychosis (Harvey et al., 2016).

\section{Subsequent adversities}

Our findings demonstrate that the association between childhood adversity and subsequent adversity previously recognised within the general population (e.g. Briere and Elliott, 2003; Casey and Nurius, 2005) is also evident in people with psychosis. For all participants, exposure to a definite psychosocial stressor within the 12 months preceding illness onset was high (63\%) as was recent victimisation (39\%). Those participants reporting any form of childhood adversity (and those who had experienced sexual abuse or other forms of abuse) had a higher rate of reporting a definite psychosocial stressor within 12 months of illness onset and also recent victimisation. These findings are consistent with the possibility that perceived social threat is a key risk factor for psychosis (van Nierop et al., 2014). This also supports cognitive models of psychosis that suggest particular psychotic symptoms may be best conceptualised as dimensional such that expression of these symptoms is linked to exposure to cumulative adverse events beginning in childhood. This may also be associated with 
Table 4. Sensitivity analysis 3: logistic regression models estimating the effect of sexual abuse, other abuse and interpersonal loss (hierarchically coded) on 18 variables measuring symptoms, diagnoses and measures of functioning, $n=1793$

\begin{tabular}{|c|c|c|c|c|c|c|}
\hline Outcomes & $\begin{array}{l}\text { Sexual abuse } \\
\text { AOR }(95 \% \mathrm{CI})\end{array}$ & $p$-value & $\begin{array}{l}\text { Other abuse } \\
\text { AOR }(95 \% \mathrm{Cl})\end{array}$ & $p$-value & $\begin{array}{l}\begin{array}{c}\text { Interpersonal } \\
\text { loss }\end{array} \\
\text { AOR }(95 \% \mathrm{CI})\end{array}$ & $p$-value \\
\hline \multicolumn{7}{|l|}{ Symptom and symptom clusters } \\
\hline Depression (lifetime) & $2.16(1.38-3.37)$ & 0.001 & $1.47(0.99-2.19)$ & 0.058 & $0.92(0.72-1.18)$ & 0.504 \\
\hline Mania (lifetime) & $1.25(0.96-1.64)$ & 0.101 & $0.89(0.67-1.18)$ & 0.411 & $0.99(0.82-1.21)$ & 0.948 \\
\hline Self-reproach (lifetime) & $1.64(1.25-2.15)$ & $<0.001$ & $1.44(1.09-1.92)$ & 0.011 & $0.70(0.57-0.86)$ & 0.001 \\
\hline Delusions (lifetime) & $1.04(0.71-1.52)$ & 0.833 & $1.40(0.90-2.19)$ & 0.137 & $0.83(0.62-1.10)$ & 0.195 \\
\hline Hallucinations (lifetime) & $1.53(1.08-2.18)$ & 0.017 & $1.42(0.99-2.04)$ & 0.056 & $0.86(0.68-1.09)$ & 0.221 \\
\hline Subjective thought disorder (lifetime) & $1.64(1.25-2.15)$ & $<0.001$ & $1.34(1.01-1.76)$ & 0.040 & $0.85(0.70-1.03)$ & 0.105 \\
\hline Suicidal thoughts (last 4 weeks) & $1.56(1.08-2.26)$ & 0.018 & $1.43(0.97-2.10)$ & 0.071 & $0.87(0.65-1.17)$ & 0.351 \\
\hline Self-harm (past 12 months) & $1.79(1.31-2.45)$ & $<0.001$ & $1.22(0.86-1.73)$ & 0.268 & $0.80(0.62-1.03)$ & 0.088 \\
\hline Anxiety (past 12 months) & $1.56(1.16-2.11)$ & 0.003 & $1.56(1.15-2.11)$ & 0.004 & $0.87(0.72-1.07)$ & 0.185 \\
\hline Negative syndrome (past 12 months) & $1.39(1.03-1.88)$ & 0.031 & $1.24(0.90-1.69)$ & 0.184 & $0.75(0.61-0.93)$ & 0.009 \\
\hline \multicolumn{7}{|l|}{ Diagnosis } \\
\hline $\begin{array}{l}\text { Alcohol and other substance dependence } \\
\text { excluding cannabis (lifetime) }\end{array}$ & $1.17(0.86-1.59)$ & 0.307 & $1.23(0.89-1.69)$ & 0.212 & $1.03(0.82-1.28)$ & 0.815 \\
\hline Affective psychosis (lifetime) & $1.22(0.90-1.65)$ & 0.197 & $1.17(0.85-1.62)$ & 0.334 & $0.85(0.67-1.07)$ & 0.167 \\
\hline Non-affective psychosis (lifetime) & $0.96(0.72-1.27)$ & 0.777 & $1.00(0.74-1.35)$ & 0.998 & $0.95(0.77-1.17)$ & 0.609 \\
\hline \multicolumn{7}{|l|}{ Functioning } \\
\hline Social dysfunction (past 12 months) & $1.40(0.98-2.00)$ & 0.066 & $1.42(0.95-2.11)$ & 0.083 & $0.92(0.71-1.19)$ & 0.534 \\
\hline Victimisation (past 12 months) & $1.48(1.14-1.94)$ & 0.004 & $1.64(1.25-2.16)$ & $<0.001$ & $0.82(0.67-0.99)$ & 0.043 \\
\hline Crime/offending (past 12 months) & $1.44(0.95-2.18)$ & 0.084 & $1.67(1.12-2.48)$ & 0.011 & $0.84(0.61-1.15)$ & 0.265 \\
\hline Homelessness (past 12 months) & $1.00(0.62-1.62)$ & 0.994 & $1.84(1.20-2.81)$ & 0.005 & $1.11(0.79-1.57)$ & 0.542 \\
\hline $\begin{array}{l}\text { Definite psychosocial stressor within } 12 \\
\text { months of first episode }\end{array}$ & $1.66(1.21-2.26)$ & 0.001 & $1.57(1.15-2.14)$ & 0.005 & $0.91(0.74-1.12)$ & 0.390 \\
\hline
\end{tabular}

Significant values are in bold.

Note: Models adjusted for age, sex, marital status, parental status, born in Australia, highest qualification obtained, family history of mental illness, socioeconomic status and lifetime cannabis use.

increased stress reactivity later in life (Perry et al., 1995; Garety et al., 2007; Bolton, 2010). It is plausible that subsequent experiences of adverse events could be an important contributor in elevating cortisol levels which in turn may affect the severity of depressive and anxiety symptoms and increase the risk of developing psychosis (Garety et al., 2007). This theory is also supported by our finding that depression and anxiety are associated with exposure to any type of childhood adversity.

\section{Positive psychotic symptoms}

We found associations between any childhood adversity and positive psychotic symptoms of hallucinations and subjective thought disorder but not delusions. Hallucinations were strongly associated with childhood sexual abuse and we found a relationship between subjective thought disorder and all forms of childhood abuse, as reported elsewhere (Schenkel et al., 2005; McCabe et al., 2012; Shah et al., 2014). While some studies have found a relationship between child abuse and delusions (Scott et al., 2007; van Nierop et al., 2014), most find a stronger association between child abuse and hallucinations. Such studies also show a dose-response relationship between the number and types of traumatic events and delusional experiences, such that a combination of child abuse and adult abuse may be a strong predictor of delusional experiences (Read et al., 2003; Scott et al., 2007). In line with other studies, we found an association between any form of childhood adversity and alcohol and other substance dependence. There were no associations between abuse and interpersonal loss and lifetime diagnoses of either affective psychosis or non-affective psychosis, consistent with a number of other reports of a lack of diagnostic specificity (Matheson et al., 2013; Shah et al., 2014; van Nierop et al., 2015). In analyses restricted to people with affective psychosis, we found a different pattern of associations to that observed for people with non-affective psychosis. However, the sample of people with affective psychosis was small making interpretation difficult. Future research could explore this issue further. Our results suggest that there may be a link between event type and the increased likelihood of particular symptomatic responses. Previous studies have also found a dose-response relationship between the severity of sexual abuse in childhood and risk of hallucinations in adulthood (Shevlin et al., 2007; Bentall et al., 2012), however this was not within the scope of our study.

\section{Negative schematic belief systems}

Those who had experienced sexual abuse had a higher likelihood of depression, more than twice that of those who had not 
experienced abuse. Further and consistent with the literature, selfharm and suicidal thoughts were associated with childhood abuse (Schenkel et al., 2005; Rosenberg et al., 2007; Read et al., 2008; Conus et al., 2009; Hooven et al., 2012; Shah et al., 2014; van Nierop et al., 2014). We also found associations between abuse experiences and self-reproach which add to existing theories regarding emotional sequelae of abuse, including negative schematic beliefs and self-appraisals, and their proposed mediating role in facilitating or maintaining psychosis (Garety et al., 2007; Gracie et al., 2007). Likewise, these findings suggest avenues for study of conceivable causal pathways and tailored psychological interventions in this population (Mueser et al., 2008).

\section{Limitations}

The cross-sectional design is a limitation of this study as is the fact that all the individuals who entered our study had a diagnosis of psychosis; we were therefore unable to compare those who had experienced childhood trauma with people who had similar experiences in the general population. Recall bias associated with retrospective reporting of adversity is possible, although retrospective methods tend to bias towards under-reporting rather than over-reporting (Varese et al., 2012). Although carefully operationalised according to recognised definitions (Shah et al., 2014), our abuse types were based on a single question. The presence of these was determined from a single open-ended question about other distressing or traumatic events in childhood, with detailed notes taken and responses coded into categories. However, this may have further contributed to underreporting. Further, we recognise the limitations of using dichotomous variables meaning some of the detail of the experience is lost. Finally, our coding scheme meant that we did not distinguish between the occurrence of physical and emotional abuse and neglect (all were coded as other abuse). Understanding how specific types of abuse and neglect in childhood may contribute to the development of mental and psychosocial impairment in adulthood would be a useful focus of future research.

\section{Conclusions}

In our sample of people living with psychosis, adverse events in childhood, especially interpersonal loss, were common and suggest a need for appropriate and targeted prevention. Sexual abuse and other types of abuse were less common but may lead to elevated risk of poorer mental health and poorer psychosocial outcomes in adulthood relative to other people with psychosis. An implication of these findings is that mental health professionals should be trained to make routine and sensitive enquiries about adverse childhood events since these may have prognostic implications for mental health outcomes. Further, mental health professionals and researchers should develop and apply the evidence base for trauma-focussed interventions. Longitudinal research designs are warranted to provide stronger evidence about the risk of developing psychosis following adverse events in childhood and the potential role of subsequent psychosocial stressors. These designs should also gather more details about the exposure (e.g. age of occurrence, frequency of adverse event types and victim's relationship to perpetrator), whether disclosure occurred and what response occurred to any disclosure, in order to further improve our understanding of relationships between childhood adversity and psychosis.
Data. The 2010 Survey of High Impact Psychosis is available for approved researchers to access. Contact Professor Vera Morgan, Head: Neuropsychiatric Epidemiology Research Unit, School of Population and Global Health, University of Western Australia, email: vera.morgan@uwa. edu.au.

Acknowledgements. This publication is based on data collected in the framework of the 2010 Australian National Survey of High Impact Psychosis. In 2010, the members of the Survey of High Impact Psychosis Study Group were: V. Morgan (National Project Director), A. Jablensky (Chief Scientific Advisor), A. Waterreus (National Project Coordinator), R. Bush, V. Carr, D. Castle, M. Cohen, C. Galletly, C. Harvey, B. Hocking, A. Mackinnon, P. McGorry, J. McGrath, A. Neil, S. Saw and H. Stain. The Australian National Survey of High Impact Psychosis was funded by the Australian Government Department of Health and Ageing. This report acknowledges, with thanks, the hundreds of mental health professionals who participated in the preparation and conduct of the survey and the many Australians with psychotic disorders who gave their time and whose responses form the basis of this publication.

Author contributions. All authors contributed to the study design. Suzanne Turner and Carol Harvey conducted the review of the literature. Matthew Spittal and Suzanne Turner undertook the statistical analysis. Suzanne Turner wrote the initial draft of the manuscript in collaboration with Carol Harvey and Matthew Spittal. All authors commented on the first manuscript and contributed to writing subsequent versions. All authors approved the final manuscript.

Financial support. Matthew Spittal is a recipient of an Australian Research Council Future Fellowship (project number FT180100075) funded by the Australian Government.

Conflict of interest. None.

Ethical standards. Ethics approvals for the study were obtained from relevant institutional human research ethics committees.

\section{References}

Alameda L, Ferrari C, Baumann P, Gholam-Rezaee M, Do K and Conus P (2015) Childhood sexual and physical abuse: age at exposure modulates impact on functional outcome in early psychosis patients. Psychological Medicine 45, 2727-2736.

American Psychiatric Association (2000) Diagnostic and Statistical Manual of Mental Disorders: DSM-IV, 4th Edn rev. Washington, DC: American Psychiatric Association.

Australian Bureau of Statistics (2005) 4509.0 - Crime and Safety, Australia. Available at http://www.abs.gov.au/ausstats/abs@.nsf/mf/4509.0 (Accessed 6 May 2018).

Australian Bureau of Statistics (2011) Socio-Economic Indexes for Areas (SEIFA). Available at http://www.abs.gov.au/websitedbs/censushome.nsf/ home/seifa (Accessed 6 July 2018).

Australian Institute of Health and Welfare (2012) Child Protection Australia 2010-11. Child Welfare Series no. 53. Cat. no. CWS 41. Canberra: AIHW.

Bebbington P, Jonas S, Kuipers E, King M, Cooper C, Brugha T, Meltzer H, McManus S and Jenkins R (2011) Childhood sexual abuse and psychosis: data from a cross-sectional national psychiatric survey in England. British Journal of Psychiatry 199, 29-37.

Bendall S, Jackson H, Hulbert C and McGorry P (2008) Childhood trauma and psychotic disorders: a systematic, critical review of the evidence. Schizophrenia Bulletin 34, 568-579.

Bentall R, Wickham S, Shevlin M and Varese F (2012) Do specific early-life adversities lead to specific symptoms of psychosis? A study from the 2007 Adult Psychiatric Morbidity Survey. Schizophrenia Bulletin 38, 734-740.

Berthelot N, Paccalet T, Gilbert E, Moreau I, Merette C, Gingras N, Rouleau N and Maziade M (2015) Childhood abuse and neglect may induce deficits in cognitive precursors of psychosis in high-risk children. Journal of Psychiatry and Neuroscience 40, 336-343. 
Bolton D (2010) Social, biological and person constructions of mental illness. In Morgan C and Bhugra D (eds), Principles of Social Psychiatry. Chichester, West Sussex: John Wiley \& Sons, Ltd, pp. 39-50.

Briere J and Elliott D (2003) Prevalence and psychological sequelae of selfreported childhood physical and sexual abuse in a general population sample of men and women. Child Abuse and Neglect 27, 1205-1222.

Cantor-Graae E (2007) The contribution of social factors to the development of schizophrenia: a review of recent findings. Canadian Journal of Psychiatry 52, 277-286.

Casey E and Nurius P (2005) Trauma exposure and sexual re-victimisation risk: comparisons across single, multiple incident and multiple perpetrator victimisations. Violence Against Women 11, 505-530.

Castle D, Jablensky A, McGrath J, Carr V, Morgan V, Waterreus A, Valuri G, Stain H, McGuffin P and Farmer A (2006) The diagnostic interview for psychoses (DIP): development, reliability and applications. Psychological Medicine 36, 69-80.

Conus P, Cotton S, Schimmelmann B, McGorry P and Lambert M (2009) Pretreatment and outcome correlates of sexual and physical trauma in an epidemiological cohort of first-episode psychosis patients. Schizophrenia Bulletin 36, 1105-1114.

Cotter J, Kaess M and Yung A (2015) Childhood trauma and functional disability in psychosis, bipolar disorder and borderline personality disorder: a review of the literature. Irish Journal of Psychological Medicine 32, 21-30.

Craig T (2010) Depression. In Morgan C and Bhugra D (eds), Principles of Social Psychiatry. Chichester, West Sussex: John Wiley and Sons, Ltd, pp. 215-226.

Cristobal-Narvaez P, Sheinbaum T, Ballespi S, Mitjavila $M$, Myin-Germeys I, Kwapil T and Barrantes-Vidal N (2016) Impact of adverse childhood experiences on psychotic-like symptoms and stress reactivity in daily life in nonclinical young adults. PLoS One 11, e0153557.

Cutajar M, Mullen P, Ogloff J, Thomas S, Wells D and Spataro J (2010) Psychopathology in a large cohort of sexually abused children followed up to 43 years. Child Abuse and Neglect 34, 813-822.

Darke S, Ward J, Hall W, Heather N and Wodak A (1991) The Opiate Treatment Index (OTI) Manual. New South Wales: National Drug and Alcohol Research Centre.

Felitti V, Anda R, Nordenberg D, Williamson D, Spitz A, Edwards V, Koss M and Marks J (1998) Relationship of childhood abuse and household dysfunction to many of the leading causes of death in adults. The Adverse Childhood Experiences (ACE) Study. American Journal of Preventative Medicine 14, 245-258.

Fossey E and Harvey C (2001) A conceptual review of functioning: implications for the development of consumer outcome measures. Australian and New Zealand Journal of Psychiatry 35, 91-98.

Gallagher B and Jones B (2016) Neglect and hereditary risk: their relative contribution to schizophrenia with negative symptomatology. International Journal of Social Psychiatry 62, 235-242.

Garety P, Bebbington P, Fowler D, Freeman D and Kuipers E (2007) Implications for neurobiological research of cognitive models of psychosis: a theoretical paper. Psychological Medicine 37, 1377-1391.

Gil A, Gama C, de Jesus D, Lobato $M$, Zimmer $M$ and Belmonte-de-Abreu P (2009) The association of child abuse and neglect with adult disability in schizophrenia and the prominent role of physical neglect. Child Abuse and Neglect 33, 618-624.

Gilbert R, Widom C, Browne K, Fergusson D, Webb E and Janson S (2009) Burden and consequences of child maltreatment in high-income countries. Lancet 373, 68-81.

Gonzalez A, Boyle M, Kyu H, Georgiades K, Duncan L and MacMillan H (2012) Childhood and family influences on depression, chronic physical conditions, and their comorbidity: findings from the Ontario Child Health Study. Journal of Psychiatric Research 46, 1475-1482.

Gracie A, Freeman D, Green S, Garety P, Kuipers E, Hardy A, Ray K, Dunn G, Bebbington P and Fowler D (2007) The association between traumatic experience, paranoia and hallucinations: a test of the predictions of psychological models. Acta Psychiatrica Scandinavica 116, 280-289.

Gustafson T and Sarwer D (2004) Childhood sexual abuse and obesity. Obesity Reviews 5, 129-135.

Harvey C, Brophy L, Parsons S, Moeller-Saxone K, Grigg M and Siskind D (2016) People living with psychosocial disability: rehabilitation and recovery-informed service provision within the second Australian national survey of psychosis. Australian and New Zealand Journal of Psychiatry 50, 534-547.

Holshausen K, Bowie C and Harkness K (2016) The relation of childhood maltreatment to psychotic symptoms in adolescents and young adults with depression. Journal of Clinical Child and Adolescent Psychology 45, 241-247.

Hooven C, Nurius P, Logan-Greene P and Thompson E (2012) Childhood violence exposure: cumulative and specific effects on adult mental health. Journal of Family Violence 27, 511-522.

Jablensky A, McGrath J, Herrman H, Castle D, Gureje O, Evans M, Carr V, Morgan V, Korten A and Harvey C (2000) Psychotic disorders in urban areas: an overview of the study on low prevalence disorders. Australian and New Zealand Journal of Psychiatry 34, 221-236.

Janssen I, Krabbendam L, Bak M, Hanssen M, Vollebergh W, de Graaf R and van Os J (2004) Childhood abuse as a risk factor for psychotic experiences. Acta Psychiatrica Scandinavica 109, 38-45.

Killackey E, Harvey C, Amering M and Herrman H (2015) Partnerships for meaningful community living: rehabilitation and recovery-informed practices. In Tasman A, Kay J, Lieverman J, First M and Riba M (eds) Psychiatry. Chichester, West Sussex: John Wiley and Sons, Ltd, pp. 1959-1982.

Kirkpatrick B, Buchanan R, McKenney P, Alphs L and Carpenter W (1989) The schedule for the Deficit Syndrome: an instrument for research in schizophrenia. Psychiatry Research 30, 119-123.

Lataster J, Myin-Germeys I, Lieb R, Wittchen H and van Os J (2012) Adversity and psychosis: a 10-year prospective study investigating synergism between early and recent adversity in psychosis. Acta Psychiatrica Scandinavica 125, 388-399.

Matheson S, Shepherd A, Pinchbeck R, Laurens K and Carr V (2013) Childhood adversity in schizophrenia: a systematic meta-analysis. Psychological Medicine 43, 225-238.

Mauritz M, Goossens P, Draijer N and van Achterberg T (2013) Prevalence of interpersonal trauma exposure and trauma-related disorders in severe mental illness. European Journal of Psychotraumatology 4. doi: 10.3402/ ejpt.v4i0.19985.

McCabe K, Maloney E, Stain H, Loughland C and Carr V (2012) Relationship between childhood adversity and clinical and cognitive features in schizophrenia. Journal of Psychiatric Research 46, 600-607.

McGuffin P, Farmer A and Harvey I (1991) A polydiagnostic application of operational criteria in studies of psychotic illness. Development and reliability of the OPCRIT system. Archives of General Psychiatry 48, 764-770.

Messman-Moore T, Walsh K and DiLillo D (2010) Emotion dysregulation and risky sexual behavior in revictimization. Child Abuse and Neglect 34, 967-976.

Misiak B, Krefft M, Bielawski T, Moustafa A, Sasiadek M and Frydecka D (2017) Toward a unified theory of childhood trauma and psychosis: a comprehensive review of epidemiological, clinical, neuropsychological and biological findings. Neuroscience and Biobehavioral Reviews 75, 393-406.

Moore E, Romaniuk H, Olsson C, Jayasinghe Y, Carlin J and Patton G (2010) The prevalence of childhood sexual abuse and adolescent unwanted sexual contact among boys and girls living in Victoria, Australia. Child Abuse and Neglect 34, 379-385.

Morgan C and Fisher H (2007) Environment and schizophrenia: environmental factors in schizophrenia: childhood trauma -a critical review. Schizophrenia Bulletin 33, 3-10.

Morgan V, Waterreus A, Jablensky A, Mackinnon A, McGrath J, Carr V, Bush R, Castle D, Cohen M, Harvey C, Galletly C, Stain H, Neil A, McGorry P, Hocking B, Shah S and Saw S (2012) People living with psychotic illness in 2010. An overview of findings from the second Australian national survey of psychosis. Australian and New Zealand Journal of Psychiatry 46, 735-752.

Morgan V, McGrath J, Jablensky A, Badcock J, Wattereus A, Bush R, Carr V, Castle D, Cohen M, Galletly C, Harvey C, Hocking B, McGorry P, Neil A, Saw S, Shah S, Stain H and Mackinnon A (2014) Psychosis prevalence and physical, metabolic and cognitive co-morbidity: data from the second Australian National Survey of Psychosis. Psychological Medicine 44, 2163-2176.

Morosini P, Magliano L, Brambilla L, Ugolini S and Pioli R (2000) Development, reliability and acceptability of a new version of the 
DSM-IV Social and Occupational Functioning Assessment Scale (SOFAS) to assess routine social functioning. Acta Psychiatrica Scandinavica 101, 323-329.

Mueser K, Rosenberg S, Xie H, Jankowski M, Bolton E and Lu W (2008) A randomized controlled trial of cognitive-behavioral treatment for posttraumatic stress disorder in severe mental illness. Journal of Consulting and Clinical Psychology 76, 259-271.

National Mental Health Commission (2014) The National Review of Mental Health Programmes and Services. Sydney: National Mental Health Commission.

Palmier-Claus J, Berry K, Bucci S, Mansell W and Varese F (2016) Relationship between childhood adversity and bipolar affective disorder: systematic review and meta-analysis. British Journal of Psychiatry 209, 454-459.

Pereda N, Guilera G, Forns M and Gomez-Benito J (2009) The prevalence of child sexual abuse in community and student samples: a meta-analysis. Clinical Psychology Review 29, 328-338.

Perry B, Pollard R, Blakey T, Baker W and Vigilante D (1995) Childhood trauma, the neurobiology of adaptation, and 'use-dependent' development of the brain: how 'states' become 'traits'. Infant Mental Health Journal 16, 271-291.

Pluck G, Lee K, David R, Macleod D, Spence S and Parks R (2011) Neurobehavioural and cognitive function is linked to childhood trauma in homeless adults. British Journal of Clinical Psychology 50, 33-45.

Poon AWC, Harvey C, Mackinnon A and Joubert L (2017) A longitudinal population-based study of carers of people with psychosis. Epidemiology and Psychiatric Sciences 26, 265-275.

Read J, Agar K, Argyle N and Aderhold V (2003) Sexual and physical abuse during childhood and adulthood as predictors of hallucinations, delusions and thought disorder. Psychology and Psychotherapy: Theory, Research and Practice 76, 1-22.

Read J, Fink P, Tudegeir T, Felitti V and Whitfield C (2008) Child maltreatment and psychosis: a return to a genuinely integrated bio-psycho-social model. Clinical Schizophrenia and Related Psychoses 2, 235-254.

Robinson C (2003) Understanding Iterative Homelessness: The Case of People with Mental Disorders (Final Report No. 45). Sydney: Australian Housing and Urban Research Institute, pp. 1-55.

Rosenberg SD, Lu W, Mueser KT, Jankowski MK and Cournos F (2007) Correlates of adverse childhood events among adults with schizophrenia spectrum disorders. Psychiatric Services 58, 245-253.

Rosenman S and Rodgers B (2004) Childhood adversity in an Australian population. Social Psychiatry and Psychiatric Epidemiology 39, 695-702.

Schenkel L, Spaulding W, DiLillo D and Silverstein S (2005) Histories of childhood maltreatment in schizophrenia: relationships with premorbid functioning, symptomatology, and cognitive deficits. Schizophrenia Research 76, 273-286.
Scott J, Chant D, Andrews G, Martin G and McGrath J (2007) Association between trauma exposure and delusional experiences in a large communitybased sample. British Journal of Psychiatry 190, 339-343.

Shah S, Mackinnon A, Galletly C, Carr V, McGrath J, Stain H, Castle D, Harvey C, Sweeney S and Morgan V (2014) Prevalence and impact of childhood abuse in people with a psychotic illness. Data from the second Australian National Survey of Psychosis. Schizophrenia Research 159, 20-26.

Shevlin M, Dorahy M and Adamson G (2007) Childhood traumas and hallucinations: an analysis of the National Comorbidity Survey. Journal of Psychiatric Research 41, 222-228.

Stolerman I and Price L (2015) Functional outcome. In Stolerman I and Price L (eds), Encyclopedia of Psychopharmacology. Berlin, Heidelberg: Springer, 546-547.

Trauelsen A, Bendall S, Jansen J, Nielsen H, Pedersen M, Trier C, Haahr U and Simonsen E (2015) Childhood adversity specificity and dose-response effect in non-affective first-episode psychosis. Schizophrenia Research 165 , $52-59$.

Van der Kolk B, Roth S, Pelcovitz D, Sunday S and Spinazzola J (2005) Disorders of extreme stress: the empirical foundation of a complex adaptation to trauma. Journal of Traumatic Stress 18, 389-399.

van Nierop M, Lataster T, Smeets F, Gunther N, van Zelst C, de Graaf R, ten Have M, van Dorsselaer S, Bak M, Myin-Germeys I and Viechtbauer W (2014) Psychopathological mechanisms linking childhood traumatic experiences to risk of psychotic symptoms: analysis of a large, representative population-based sample. Schizophrenia Bulletin 40, S123-S130.

van Nierop M, Viechtbauer W, Gunther N, van Zelst C, de Graaf R, ten Have M, van Dorsselaer S, Bak M and van Winkel R (2015) Childhood trauma is associated with a specific admixture of affective, anxiety, and psychosis symptoms cutting across traditional diagnostic boundaries. Psychological Medicine 6, 1277-1288.

Varese F, Smeets F, Drukker M, Lieverse R, Lataster T, Viechtbauer W, Read J, van Os J and Bentall R (2012) Childhood adversities increase the risk of psychosis: a meta-analysis of patient-control, prospective- and cross-sectional cohort studies. Schizophrenia Bulletin 38, 661-671.

Wing J, Babor T, Brugha T, Burke J, Cooper J, Giel R, Jablenski A, Regier D and Sartorius N (1990) SCAN. Schedules for clinical assessment in neuropsychiatry. Archives of General Psychiatry 47, 589-593.

Wing J, Curtins R and Beevor A (1999) Health of the Nation Outcome Scales (HoNOS): glossary for HoNOS score sheet. British Journal of Psychiatry 174, 432-434.

World Health Organisation (1992) The ICD-10 Classification of Mental and Behavioural Disorders. Geneva: World Health Organisation.

World Health Organisation (2015) International Classification of Diseases (ICD-10). Available at http://apps.who.int/classifications/icd10/browse/ 2015/en (Accessed 20 May 2018). 